\title{
DESENVOLVIMENTO DE UM DISPOSITIVO PARA PREVENIR A EXPOSIÇÃO A ALTAS TEMPERATURAS
}

\author{
Jordana de Souza Nogueira (UFCG) jordanadesouzanogueira@gmail.com \\ Marcielly Medes Lima (UFCG) marciellymendes1@gmail.com \\ Fernanda Santos Souza (UFCG) nandasantosj3@gmail.com
}

\section{Resumo}

Há muitos segmentos industriais que possuem processos que demandam altíssimas temperaturas pra serem realizados, como: siderúrgica, metalurgia e ramo alimentício. Esses ambientes são considerados críticos, devido à exposição humana a altas taxas de calor, e por isso ocasionam grandes números de acidentes de trabalho. Diante disso surge a necessidade de medidas preventivas, dentre elas o uso de EPC (equipamento de proteção coletiva). O presente artigo tem a intenção de desenvolver um EPC, intencionado em analisar a temperatura do ambiente de trabalho. A metodologia foi baseada em um estudo de caso em uma pizzaria onde um dispositivo de arduíno desenvolvido identificará a temperatura a qual o funcionário está exposto a fim de alertá-lo quando a mesma estiver acima de $31,4^{\circ} \mathrm{C}$ (limite permitido pela NR-15). Para evidenciar o funcionamento do dispositivo, a aplicação dessa metodologia na pizzaria foi realizada.

Palavras-Chaves: (Temperatura; Arduíno; EPC)

\section{Introdução}

A Saúde e Segurança do Trabalho (SST) no Brasil, é auxiliada por Leis e Normas Regulamentadoras (NRs) que estabelecem prescrições para que as empresas se certifiquem aos cuidados da saúde e segurança de seus empregados. No processo produtivo, a área obedecendo aos conformes da normatização, minimiza os custos ocasionados por acidentes e lesões de trabalho. (SESCON-SP, 2019).

No cenário brasileiro, exemplando o ramo culinário, as empresas expõem seus funcionários a temperaturas que ultrapassam o limite de segurança, de modo a preservar a segurança dos trabalhadores, desenvolvem-se estudos, normas e necessidades por partes do governo para que os profissionais desta área tenham uma melhor qualidade de trabalho. 
Segundo o Ministério de Trabalho e Previdência Social (MTPS) o número de acidentes de trabalho no setor de serviços representa $55 \%$ do total em 2017, desses, $4 \%$ é referente a serviços de alimentação e alojamento (que contabilizou 11.381 acidentes, no ano).

A temperatura humana é de acordo com o controle homeotérmico, pois é mantida em referente estabilidade a $37^{\circ} \mathrm{C}$ (IIDA, 1997). Há a prevalência de tal temperatura de $37^{\circ} \mathrm{C}$ no cérebro, coração e órgão abdominais, sendo que sua manutenção é essencial para a realização de processos metabólicos. Na superfície da pele e no interior dos músculos as temperaturas podem apresentar variações de acordo com a exposição à temperatura ambiente e a atividade realizada (GRANDJEAN, 1998, p. 289).

Sabendo-se disso surgiu a necessidade de criar um dispositivo Arduíno, o qual tem por objetivo informar aos funcionários a temperatura a qual estão expostos, seja vulnerável a temperatura do ambiente ou aos instrumentos utilizados para a produção.

\section{Referencial Teórico}

\subsection{Higiene e Segurança do Trabalho}

\subsubsection{Segurança do Trabalho}

Segurança do trabalho pode ser entendida como os conjuntos de medidas que são adotadas visando minimizar os acidentes de trabalho, doenças ocupacionais, bem como proteger a integridade e a capacidade de trabalho do trabalhador. (ALBUQUERQUE, 2017).

\subsubsection{Higiene Ocupacional}

Higiene Ocupacional é a ciência que tem como principal função antecipar, reconhecer, avaliar e controlar os perigos para a saúde no ambiente de trabalho com o objetivo de proteger a higidez e o bem-estar dos trabalhadores e da comunidade em geral. (MARQUES, 2017).

Segundo Marques (2017), a higiene ocupacional: visa cuidar do trabalhador em três aspectos:

Saúde Física: Cuidados para que os movimentos realizados durante o trabalho não causem lesões ao funcionário.

Saúde Mental: Preocupa-se com o bem-estar mental do colaborador, a fim de que ele não seja exposto a situações altamente estressantes ou constrangedoras que possam prejudicá-lo. 
Saúde Social: Tem como objetivo promover uma boa relação entre todos os funcionários, para que eles convivam de forma pacífica e harmoniosa.

\subsubsection{Acidente de Trabalho}

É o que ocorre pelo exercício do trabalho a serviço da empresa ou instituição, provocando lesão corporal ou perturbação funcional que cause a morte, a perda ou a redução, permanente ou temporária, da capacidade para o trabalho. (RODRIGUES, 2017)

\subsubsection{Riscos Ocupacionais}

Risco é definido por toda e qualquer possibilidade de que algum elemento ou circunstância existente num dado processo ou ambiente de trabalho possa causar dano à saúde, seja por meio de acidentes, doenças ou do sofrimento dos trabalhadores, ou ainda por poluição ambienta. (SILVA et al, 2012).

A Norma Regulamentadora NR-05 classifica os riscos em:

Riscos Físicos: ruídos, vibrações, radiações ionizantes e não ionizantes pressões anormais, temperaturas extremas, iluminação deficiente, umidade, etc.

Riscos Químicos: poeiras, fumos névoas, vapores, gases, produtos químicos em geral, neblina, etc.

Riscos Biológicos: vírus, bactérias, protozoários, fungos, bacilos, parasitas, insetos, cobras, aranhas, etc.

Riscos Ergonômicos: trabalho físico pesado, posturas incorretas, treinamento inadequado/inexistente, trabalhos em turnos, trabalho noturno, atenção e responsabilidade, monotonia, ritmo excessivo, etc.

Riscos de Acidentes: arranjo físico inadequado, máquinas e equipamentos sem proteção, ferramentas inadequadas ou defeituosas, iluminação inadequada, eletricidade, probabilidade de incêndio ou explosão, armazenamento inadequado, animais peçonhentos, outras situações de risco que poderão contribuir para a ocorrência de acidentes.

\subsection{NR 15 - Atividades e operações insalubres}


A NR-15 é um conjunto de normas que estabelece e disciplina o que é classificado um trabalho insalubre. A vigência desta norma é imprescindível porque, de acordo com a legislação trabalhista presente, colaboradores em circunstâncias insalubres ganham um acréscimo no salário, de acordo com as condições às quais são submetidos. Quanto mais grave ou intensa é considerada a insalubridade, maior é o acréscimo no salário, limitado a 40\%. (XAVIER et al., 2019).

O Anexo 3 - da Norma Regulamentadora tem como objetivo estabelecer limites de exposição a serem utilizados como indicadores na avaliação, prevenção e controle dos riscos decorrentes da exposição ao calor.

Tabela 1 - Taxa de metabolismo por tipo de atividade

\begin{tabular}{cc}
\hline TIPO DE ATIVIDADE & Kcal/h \\
\hline Sentado em repouso & 100 \\
Trabalho leve & $125-150$ \\
Trabalho Moderado & $180-300$ \\
Trabalho Pesado & $440-550$ \\
\hline Fonte: Adaptado da Norma Regulamentadora NR15 (2019)
\end{tabular}

Quadro 1 - Limite de temperatura por classificação de atividade e tempo de exposição

\begin{tabular}{|c|c|c|c|}
\hline \multirow{2}{*}{$\begin{array}{c}\text { REGIME DE TRABALHO } \\
\text { INTERMITENTE COM DESCANSO NO } \\
\text { PRÓPRIO LOCAL DE TRABALHO } \\
\text { (por hora) }\end{array}$} & \multicolumn{3}{|c|}{ TIPO DE ATIVIDADE } \\
\hline & LEVE & MODERADA & PESADA \\
\hline Trabalho contínuo & até 30,0 & até 26,7 & até 25,0 \\
\hline $\begin{array}{l}45 \text { minutos trabalho } \\
15 \text { minutos descanso }\end{array}$ & 30,1 a 30,5 & 26,8 a 28,0 & 25,1 a 25,9 \\
\hline $\begin{array}{l}30 \text { minutos trabalho } \\
30 \text { minutos descanso }\end{array}$ & 30,7 a 31,4 & 28,1 a 29,4 & 26,0 a 27,9 \\
\hline $\begin{array}{l}15 \text { minutos trabalho } \\
45 \text { minutos descanso }\end{array}$ & 31,5 a 32,2 & 29,5 a 31,1 & 28,0 a 30,0 \\
\hline $\begin{array}{l}\text { Não é permitido o trabalho, sem a adoção de } \\
\text { medidas adequadas de controle }\end{array}$ & acima de 32,2 & acima de 31,1 & acima de 30,0 \\
\hline
\end{tabular}

Fonte: Norma Regulamentadora NR15 (2020)

\subsection{Arduíno}


O Arduíno é uma placa de circuito microcontrolador para desenvolvimento de protótipos eletrônicos, que permite a gravação de um conjunto de instruções através de uma linguagem de programação de modo a minimizar complexidades (FRIZZARIN, 2016).

Segundo Fonseca (2017), uma placa dessas geralmente é usada para automação de projetos eletrônicos e/ou robóticos, feito por amadores e também por profissionais. Ela facilita a prototipagem, implementação ou emulação do controle de sistema interativo, seja ele doméstico, comercial ou móvel.

O Arduíno não só facilita a programação, por meio de instruções da linguagem, como também facilita a utilização do hardware devido ao formato da sua plataforma. Mais do que os simples pinos, foram desenvolvidas placas que integram e expandem as conexões e funções da placa, permitindo ao Arduíno conexão à rede internet, wireless, GSM, comunicação RF (Radiofrequência), etc. Essas placas chamadas de Shields, se encaixam aos pinos da placa e permitem a comunicação de forma simples com demais dispositivos, estendendo o alcance da aplicação em que o Arduíno está inserido (MONK, 2015).

Segundo Gomes (2015), as aplicações do Arduíno são basicamente ilimitadas e dependem muito mais da criatividade e disciplina do desenvolvedor do que das limitações da plataforma ou das dificuldades de programação. Os makers estão usando a plataforma em projetos que vão desde a automação de processos em empresas até obras de arte.

O Arduíno pode ser especialmente útil na automatização dos processos da sua empresa. É possível criar protótipos que permitam a comunicação de um dispositivo móvel com máquinas de indústria até a integração total do escritório (luzes, aparelhos, ar-condicionado, etc) com a internet. (GOMES, 2015).

\section{Metodologia}

A pesquisa realizada neste trabalho classifica-se como uma pesquisa quantitativa. De acordo com Knechtel (2014), este tipo de pesquisa está ligada à investigação empírico-descritiva, quando se procura descobrir e classificar a relação entre as variáveis, as relações de causa e efeito entre os diferentes fenômenos. 
A inspeção sucedeu-se em uma pizzaria na cidade de Sumé, onde a atenção foi direcionada ao trabalho realizado pelo responsável do forno, em que foi identificada a exposição do trabalhador a altas taxas de calor. $\mathrm{O}$ ambiente em que o forno fica posicionado foi verificado, e por meio do equipamento Termômetro de globo digital com datalogger (IBUTG) modelo TD-500 Plus, com auxílio de um técnico de segurança do trabalho, foi aferido à temperatura predominante no local. No decurso de uma hora, analisou-se o tempo em que o trabalhador realizava a atividade próxima ao forno e o tempo em que tinha de descanso, por meio da cronometragem.

Dessa forma, através dos dados obtidos foi elaborado por meio do uso de Arduino, um dispositivo. O equipamento foi construído mediante a utilização de uma placa protoboard, uma placa de arduino, alguns jampers, um cabo USB, um resistor de $10 \mathrm{~K}$, um sensor de temperatura, um potenciômetro, display e buzzer.

O processo de construção iniciou-se com a ligação do sensor de temperatura onde foi utilizado o resistor de $10 \mathrm{~K}$ conectado a um terra (5V) e um GND (negativo), aplicando-o a uma porta analógica para recebimento dos dados, logo após, foram utilizadas as portas 4,5,6,7,8 e 9 para a ligação do display LCD, sendo este acoplado a um potenciômetro para o ajuste do contraste, e por último a instalação do buzzer, para que ao ser atingida a temperatura programada haja a emissão de um sinal sonoro.

\section{Resultados e Discussões}

Com o intuito de estabelecer parâmetros para o funcionamento do arduíno e atestar a necessidade de utilização do mesmo, realizou-se o estudo do ambiente na pizzaria. Como resultado da analise de desempenho e duração da tarefa, caracterizou-se como atividade leve tendo em vista que o funcionário no intervalo de uma hora, trabalha cerca de 30 minutos e tem 30 minutos de descanso, e ainda que a temperatura predominante no local era de $32,4^{\circ} \mathrm{C}$, ultrapassando $31,4^{\circ} \mathrm{C}$ (limite permitido pela norma NR15), constatando-se a necessidade de utilização do arduíno.

Após o a confirmação da necessidade de utilização, foi construído o dispositivo. 
Figura 1 - Circuito de ligações

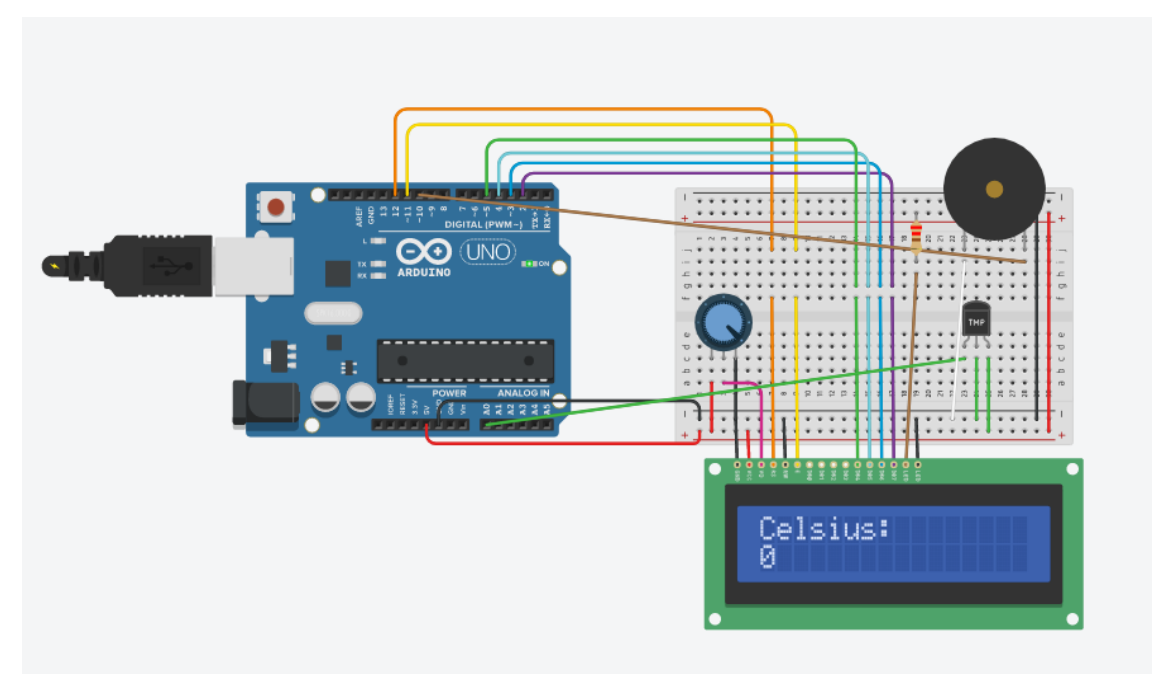

Fonte: Próprios Autores (2020)

Para demonstrar o funcionamento do dispositivo foram realizados alguns testes. $\mathrm{O}$ arduíno por meio do display mostra no leitor quanto é o valor da temperatura em graus célsius no local, apresentando $36,77^{\circ} \mathrm{C}$, como mostra a figura 2, ultrapassando o que é estabelecido pela norma regulamentadora NR15, para atividade analisada, expondo os trabalhadores a riscos.

Figura 2 - Resultado apresentado pelo dispositivo 


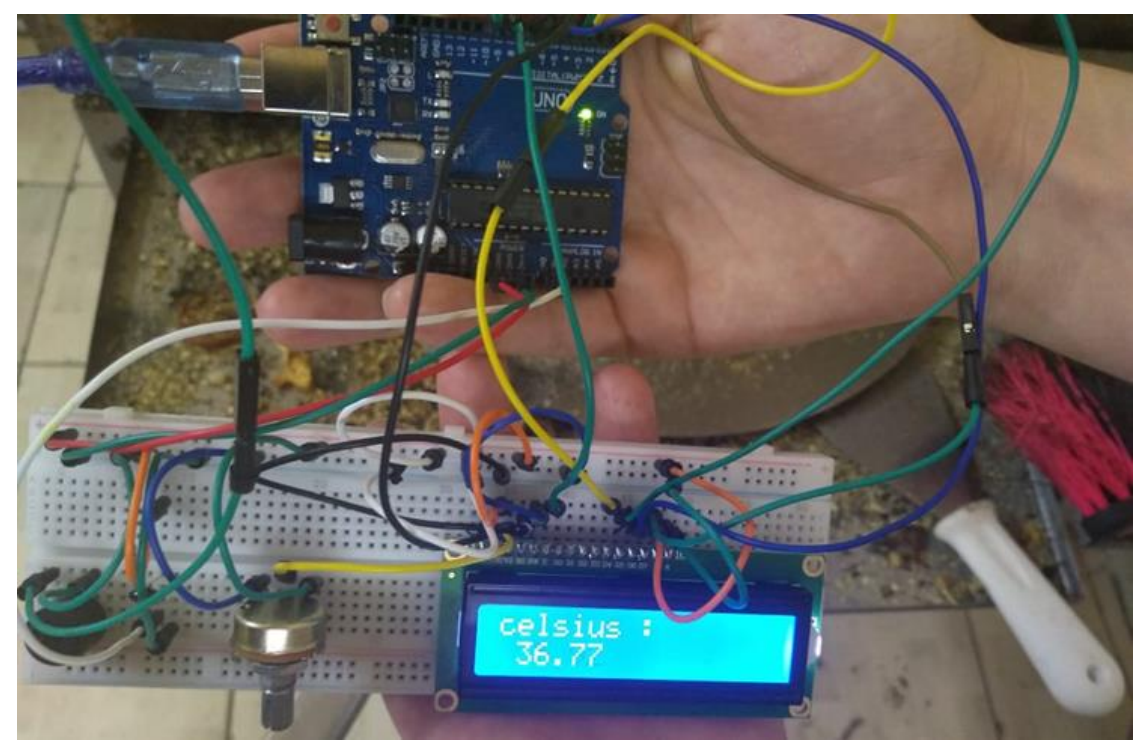

Fonte: Próprios Autores (2020)

Para prevenir que se exceda esse valor de exposição permitido, foi adicionado um buzzer que emite um sinal sonoro sempre que a temperatura estiver no limite programado, definido como seguro.

\section{Considerações Finais}

Ao constatar que o estabelecimento não possuía um sistema de controle de temperatura, e para entrar em conformidade com a NR-15 e por se tratar de uma pizzaria onde o forno atinge altas temperaturas, se faz necessária a aplicação de dispositivos que garantam a segurança e o bem estar do funcionário.

Tendo em vista o grande número de acidentes de trabalho em decorrência da exposição a altas taxas de calor, surge uma maior preocupação com a saúde do empregado a médio e longo prazo, validando o investimento e desenvolvimento de EPC's, que possam passar um feedback de forma rápida do ambiente em que o colaborador estar inserido.

Torna-se assim importante a contribuição deste artigo para o reforço do aporte teórico/prático no tocante a estudos de analise de práticas industriais ligadas a higiene e segurança do trabalho.

\section{REFERÊNCIAS}

ANGELO, Pedro D'. Pesquisa quantitativa e pesquisa qualitativa: qual a diferença?: .. 2019. .. Disponível em: <https://blog.opinionbox.com/pesquisa-quantitativa-e-pesquisa-qualitativa-qual-a-diferenca/>. Acesso em: 30 nov. 2019. 
FILIPE, D. J. Condições de trabalho em cozinhas profissionais: análise de inquéritos realizados no âmbito do Projeto COPROF. Coimbra. 2015.

FONSECA, Bruno. Arduino e suas múltiplas aplicações. 2017. Disponível em: <https://www.redbull.com/brpt/arduino-e-suas-multiplas-aplicacoes>. Acesso em: 2 dez. 2019.

GOMES, Pedro César Tebaldi. ENTENDA O QUE É ARDUINO E COMO FUNCIONA A SUA

APLICAÇÃO! 2015. Disponível em: 〈https://www.opservices.com.br/o-que-e-o-arduino/>. Acesso em: 3 dez. 2019.

MARQUES, Marcus. Tudo Que Você Precisa Saber Sobre Higiene e Segurança do Trabalho. 2017. Disponível em: <http://marcusmarques.com.br/pequenas-e-medias-empresas/voce-precisa-saber-higieneseguranca-do-trabalho/>. Acesso em: 3 dez. 2019.

MARINHO, Rogério. Esteira de Mudanças. 2019. Disponível em:

<https://www.revistasesconsp.com.br/sescon-sp-nrs-esteira-de-mudancas/>. Acesso em: 02 dez. 2019.

MASCHIO, A. C.; ALARCON, H. G.; CATAI, R. E. Análise de insalubridade em um restaurante do município de Juquitiba-SP. Fortaleza. 2015.

MONTEIRO, Luciano Fernandes; LIMA, Hugo Leonardo Moreira; SOUZA, Márcia Juliana Paiva de. A importância da saúde e segurança no trabalho nos processos logísticos. 2005. Disponível em: <file://C:/Users/Cliente/Downloads/Monteiro_LF_A\%20importancia\%20da\%20s.pdf>. Acesso em: 3 dez. 2019.

SOUSA, Wanderson Quaresma de. A IMPORTÂNCIA DA PLATAFORMA ARDUINO NO MEIO ACADÊMICO. 2018. Disponível em: <https://www.nucleodoconhecimento.com.br/engenharia-eletrica/meioacademico\#2-A-plataforma-arduino>. Acesso em: 2 dez. 2019.

XAVIER, Ana Larissa da Silva; LIMA NETO, JosÉ Silvino de; LIMA JÚNIOR, Josembergue Flôrencio de. BENZENO: PERIGO PARA A SAÚDE DOS FRENTISTAS. UMA ANÁLISE DOS RISCOS OCUPACIONAIS EM POSTOS DE COMBUSTÍVEIS NA CIDADE DE SUMÉ - PB. 2019. Disponível em: <https://www.even3.com.br/anais/7simep/142386-benzeno--perigo-para-a-saude-dos-frentistas-uma-analisedos-riscos-ocupacionais-em-postos-de-combustiveis-na-cid/>. Acesso em: 2 dez. 2019. 